\title{
MODEL PEMBELAJARAN LEMPAR TANGKAP SOFTBALLMENGGUNAKAN MEDIA PEMBELAJARAN PADA SEKOLAH MENENGAH ATAS
}

\author{
Agung Kuntoro Saputro ${ }^{1}$, Susilo ${ }^{2}$ \\ 1,2 Program Studi Pendidikan Jasmani, Universitas Negeri Jakarta \\ Jakarta, Indonesia \\ e-mail: agung122513@gmail.com, susilo_777@yahoo.com
}

\begin{abstract}
Abstrak
Penelitian ini menghasilkan model pembelajaran lempar tangkap softball menggunakan media pembelajaran pada Sekolah Menengah Atas (SMA). Penelitian ini termasuk penelitian pengembangan, dan prosedur pengembangan produk ini terdiri analisis produk yang ingin dibuat, membuat produk awal, uji validasi ahli dan revisi, uji kelompok kecil revisi, uji kelompok besar dan produk akhir. Pengumpulan data dilakukan menggunakan kuesioner yang didapat dari evaluasi ahli, serta menggunakan hasil pengamatan di lapangan yang diperoleh dari siswa, dan penerapan produk. Teknik mengolah data adalah deskriptif persentase. Data yang didapatkan adalah sebelum pemberian perlakuan (kelompok control) berupa model pembelajaran keterampilan lempar tangkap softball diketahui hasil rata-ratanya adalah 21.4 dan hasil rata-rata dari kelompok eksperimen 32.033. Maka terdapat selisih antara kelompok control dan kelompok eksperimen sebanyak 10.633. Maka model pembelajaran keterampilan lempar tangkap softball menggunakan media pembelajaran efektif dalam meningkatkan keterampilan lempar tangkap softball pada SMA. Hasil data dapat disimpulkan bahwa: (1) Model pembelajaran keterampilan lempar tangkap softball menggunakan media pembelajaran pada SMA dapat dikembangkan dan diterapkan dalam pembelajaran maupun saat ekstrakurikuler di sekolah, (2) dari model diperoleh bukti adanya peningkatan dengan ditunjukan hasil pengujian data hasil pretes dan posttest adanya perbedaan yang signifikan antara sebelum dan sesudah adanya perlakuan model
\end{abstract}

Kata-kata kunci: model, pembelajaran, lempar-tangkap, softball, media

\begin{abstract}
This research and development to produce the learning model of softball throwing skills using learning media at High School. This research includes development research, and product development procedures consist of product analysis to be made, initial product creation, expert validation test and revision, small revision group test, large group test and final product. The data were collected using questionnaires obtained from expert evaluation, and using field observations obtained from students, and product implementation. Data processing technique is descriptive percentage. The data obtained is before the treatment (control group) in the form of learning model of softball throwing skills known to the average result is 21.4 and the average result from the experimental group is 32,033 . Then there is the difference between the control group and the experimental group as much as 10,633. So the learning model of softball throwing skills using learning media at Senior High School is effective in improving
\end{abstract}


softball throwing skills at High School. The result of the data can be concluded that: (1) The learning model of softball throwing skills using the medium of learning in High School can be developed and applied in the learning as well as extracurricular in school (2) From the model obtained evidence of an increase with the results showed the test results of pretest and posttest results of a significant difference between before and after the treatment of the model.

Keywords :model, learning, throw-catch, softball, media

\section{PENDAHULUAN}

Penelitian merupakan kajian konseptual dan kerangka teoretik dalam rangka memecahkan masalah untuk tujuan tertentu, yang diawali dengan proses mengumpulkan data, mengelola, menganalisis dan menyimpulkan. Penelitian pengembangan merupakan penelitian pendekatan yang dihubungkan pada rancangan kerja dan pengembangan serta memiliki tujuan untuk perancangan dalam lingkungan pembelajaran serta mengusahakan untuk pemahaman pada fundamental secara ilmiah. Permainan softball merupakan salah satu permainan beregu yang dapat dimainkan oleh berbagai kalangan, putra-putri, anak-anak maupun orang dewasa. Permainan softball berkaitan erat dengan taktik dan strategi pertahanan dan menyerang. Teknik utama dalam softball antara lain: memukul, menangkap, dan melempar. Tujuan dari olahraga softball adalah memperoleh kemenangan dengan mendapatkan poin sebanyakbanyaknya, dengan cara melewati semua base. Permaninan Softball adalah salah satu permainan yang dapat dimainkan oleh semua golongan umur dan semua golongan manusia. Permainan softball dimainkan dengan menggunakan bola, bat, glove, dan lapangan.

Teknik dasar keterampilan gerak dalam olahraga softball meliputi: throwing (melempar), dan catching (menangkap), dan batting (memukul). Pada keterampilan tersebut yaitu rangkaian gerakan melempar, menangkap dan memukul dapat disimpulkan bahwa ketepatan menampilkan setiap detail gerak dalam setiap fase gerakan dapat diamati melalui gerak kaki tungkai, gerak lengan dan tangan, gerak togok badan, dan keserasian rangkaian seluruh gerakan.

Softball adalah permainan yang dapat merangsang kemampuan motorik siswa. Softball relative mudah untuk dilakukan, karena teknik dasar dan gerakan dasar yang harus dikuasai tidak terlalu banyak, siswa hanya dianjurkan dapat melakukan gerakan melempar, menangkap, memukul, dan berlari.Hal ini menyebabkan Softball sebagai alternative pilihan untuk menjadikan materi favorit di sekolah khususnya di tingkat pendidikan Sekolah Menengah Atas.

Berdasarkan hasil observasi dan wawancara terhadap pelaksanaan pembelajaran keterampilan lempar tangkap softball dalam mata pelajaran penjasorkes di SMA, peneliti dapat mengambil garis besar bahwa dalampembelajaran Penjasorkes pada materisoftball gerak dasar melempar dan menangkap siswa SMA masih kurang baik dalam melakukan keterampilan geraknya, dan dalam proses penyampaiannya belum dikemas secara menarik dan belum dapat mendorong siswa untuk dapat bergerak secara aktif dan bersemangat untuk mengikuti pembelajaran tersebut. Maka proses keterampilan pembelajaran 
lempar tangkap softball ini hendaknya disesuaikan dan dimodifikasi sedemikian rupa sesuai tingkat kemampuan anak SMA, dan dapat diberikan dengan berbagai variasi model gerakan maupun penggunaan media pembelajarannya, sehingga tujuan yang diinginkan tercapai.

Penggunaan media pembelajaran digunakan sebagai alat penunjang untuk menyampaikan informasi atau segala sesuatu yang dapat digunakan untuk menyampaikan pesan sehingga mampu merangsang perhatian, minat, pikiran, perasaan, dan kemauan pada diri peserta didik dalam proses kegiatan belajar untuk mencapai tujuan belajar. Berdasarkan langkah penyusunan pengembangan media pembelajaran di SMA, media yang digunakan pada pembelajaran keterampilan lempar tangkap softball disesuaikan dengan kondisi dan karakteristik siswa dan sekolah yang ada. Maka salah satu media yang dapat digunakan di SMA untuk pembelajaran keterampilan lempar tangkap softball adalah: bola tennis, bola lunak, bola reaksi atau reaction ball, bola softball, glove softball,simpai, tali, dan sasaran

Karena proses pembelajaran adalah suatu pendidikan yang dimana pendidikan adalah pengalaman peristiwa yang dialami individu agar segala sesuatu yang baru menjadi lebih terarah dan bermakna. Suherman (2000:1), menyatakan pendidikan mempunyai tujuan utama yaitu mengembangkan individu secara menyeluruh baik aspek afektif, kognitif dan psikomotor, dari tujuan utama diatas Pendidikan Jasmani dapat digunakan sebagai sarana menuju pencapaian tujuan utama tersebut. Berdasarkan hal tersebut maka peneliti tertarik untuk melakukan penelitian dengan mengembangkan model pembelajaran lempar tangkap softball menggunakan media pembelajaran pada Sekolah Menengah Atas (SMA)

\section{METODE}

Penelitian ini merupakan penelitian pengembangan yang bertujuan menghasilkan produk model pembelajaran keterampilan lempar tangkap softball menggunakan media pembelajaran pada SMA.Penelitian ini menggunakan metode dari Borg dan Gall (1983:775) yang menjelaskan metode penelitian pengembangan.

Langkah yang digunakan dalam penelitian ini adalah :

1. Melakukan penelitian pendahuluan dan pengumpulan informasi, dilakukan dengan cara observasi lapangan dan kajian pustaka.

2. Merencanakan penelitian yang akan diterapkan

3. Mendesain mengembangkan produk awal, dan desain yang telah dibuat dievaluasi bersama dengan para ahli. Ahli yang digunakan adalah satu Dosen Pembelajaran, satu Dosen Ahli Softball, dan satu Pelatih softball.

4. Selanjutnya diuji coba kelompok kecil dengan menggunakan kuisioner, konsultasi, serta evaluasi yang kemudian akan dianalisis.

5. Revisi produk awal, revisi produk awal dilakukan berdasarkan hasil evaluasi yang diberikan oleh para ahli, hasil dari revisi uji coba kelompok kecil bertujuan untuk perbaikan dan penyempurnaan produk awal yang telah dibuat.

6. Uji coba lapangan atau uji skala besar, dilakukan dengan menggunakan model produk yang sudah direvisi berdasarkan uji coba skala kecil.

7. Revisi produk, revisi produk ini dilakukan berdasarkan uji coba skala besar dan akan menyempurnakan produk akhir. 
8. Melakukan uji efektifitas untuk mengetahui model yang dibuat dapat digunakan atau tidak

9. Evaluasi produk

10. Melakukan penyebarluasan produk

\section{HASIL DAN PEMBAHASAN}

\section{Hasil}

1. Validasi Draf Produk Awal

Produk awal model pembelajaran keterampilan lempar tangkap softball terdiri dari 30 model yang telah dibuat oleh peneliti. Sebelum di uji coba peneliti melakukan validasi produk awal ke para ahli yang sesuai dengan penelitian ini. adapun para ahli yang terlibat yaitu 1 dosen ahli pembelajaran dan media pembelajaran UNJ yaitu Dr. Samsudin, M.Pd, 1 dosen ahli ahli Softball UNJ yaitu Dr. Taufik Rihatno, dan 1 Pelatih Softball yaitu Dikdik F Dermawan, M.Pd. Validasi dilakukan dengan cara memberikan draf produk awal atau 30 model yang telah dibuat oleh peneliti dengan disertai lembar evaluasi untuk para ahli. Lembar evaluasi berupa kuesioner yang berisi aspek kualitas model, saran, serta komentar dari para ahli terhadap produk pembelajaran keterampilan lempar tangkap softball menggunakan media pembelajaran pada SMA.

\section{Deskripsi Data}

Data yang sudah diperoleh dari pengisian lembar evaluasi oleh para ahlimerupakan sebagai pedoman untuk menyatakan apakah produk modelpembelajaran keterampilan lempar tangkap softball menggunakan media pembelajaran pada SMA ini dapat digunakan untuk melakukan penelitian uji coba skala kecil maupun uji coba lapangan/uji coba skala besar.

Setelah mendapatkan data dari para ahli, maka dapat dijabarkan bahwa model yang telah dibuat dapat diterapkan untuk di uji cobakan. Maka hasil data yang diperoleh dengan menggunakan produk model pembelajaran keterampilan lempar tangkap softball menggunakan media pembelajaran pada SMA dapat dijabarkan sebagai berikut:

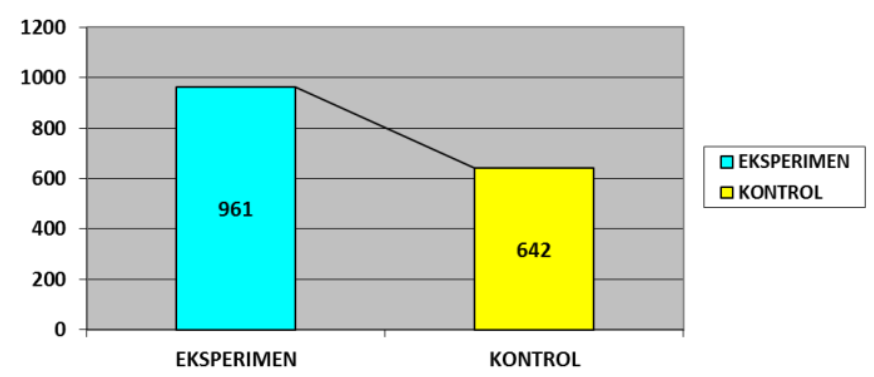

Gambar 1. Diagram Hasil Kelompok Eksperimen dan Kelompok Kontrol Pembelajaran Keterampilan Lempar Tangkap Softball Pada SMA

Berdasarkan hasil pembelajaran yang diterapkan menggunakan model Pembelajaran Keterampilan Lempar Tangkap Softball Menggunakan Media Pembelajaran Pada SMA, didapatkan data adanya peningkatan rata-rata dari sebelum dilakukan perlakuan pembelajaran menggunakan produk yang diterapkan dengan sesudah diberikan perlakuan menggunakan produk yang diterapkan.

Selisih data yang didapatkan adalah 961, artinya setelah di terapkan model pembelajaran menggunakan produk yang dibuat terdapat peningkatan sebanyak 961 poin. Atau dapat dijabarkan dengan hasil lain yaitu dengan diambilnya nilai rata-rata dari sebelum perlakuan dan sesudah perlakuan. Hasilnya adalah sebelum diberikan perlakuan rata-ratanya adalah 21.4 (kelompok control) dan setelah diberikan perlakuan dengan variasi model pembelajaran keterampilan lempar tangkap softball menggunakan media pembelajaran (kelompok eksperimen) adalah 32.033, artinya 
bahwa ada perbedaan rata-rata model pembelajaran dari sebelum dan setelah diberi perlakuan pembelajaran keterampilan lempar tangkap softball menggunakan media pembelajaran

\section{Pembahasan}

Hasil penelitian menunjukkan bahwa pengembangan model pembelajaran lempar tangkap softball menggunakan media pembelajaran pada Sekoalh Menengah Atas (SMA) efektif untuk meningkatkan keterampilan lempar tangkap softball. Hal ini dapat dilihat dari perbedaan rata-rata keterampilan lempar tangkap softball sebelum dan sesusah penggunaan model pembelajaran menggunakan media pembelajaran antara kelompok eksperimen dengan kelompok kontrol. Dimana pada kelompok yang mendapat perlakuan memperoleh rata-rata yang lebih tinggi $(32,033)$ dibandingan dengan kelompok kontrol $(21,4)$.

Hal ini menunjukkan bawah penggunaan model pembelajaran lempar tangkap berbantuan media dapat membantu siswa dalam meningkatkan keterampilan lempar tangkap sofball. Penggunaan media pembelajajaran sebagai alat pembelajaran memudahkan guru dan siswa dalam proses pembelajaran. Penggunaan media dengan modifikasi alat membuat siswa lebih berani dalam melakukan gerakangerakan lempar tangkap. Penelitian yang dilakukan oleh Yudhi dkk (2018) menunjukkan bahwa terjadi peningkatan kemampuan lempar tangkap bola kasti menggunakan media dengan modifikasi bola yang sebenarnya dengan rata-rata peningkatan sebesar 10,89.

Pengembangan model pembelajaran lempar tangkap juga pernah diteliti oleh Widiastuti dkk (2018) yang menunjukkan bahwa pengembangan model pembelajaran lempar tangkap bola pada siswa Sekolah Dasar terbukti efektif dalam meningkatkan hasil belajar siswa yang dapat dilihat dari hasil uji statistik sebelum penggunaan model $(16,12)$ dan seteralh penggunaan model $(20,24)$ yang menunjukkan terdapat perbedaan yang sugnifikan.

Penelitian yang dilakukan oleh Akbar (2015) menemukan bahwa pengembangan model-model permainan lempar tangkap untuk pembelajaran softball dalam bentuk buku panduan memudahkan untuk memahami dan dengan menambah pengetahuan baru tentang teknik dasar lempar tangkap softball. Hasil uji kelompok baik kelompok besar maupun kelompok kecil menunjukkan bahwa pengembangan model permainan lempar tangkap untuk pembelajaran softball berada pada kriteria sangat baik. Implikasi dalam penelitian pengembangan pembelajaran lempar tangkap softball menggunakan mdeiap pembelajara ini, menjadikan siswa lebih aktif dalam melakukan pembelajaran pendidikan jasmani. Pengembangan model pembelajaran lempar tangkap ini diharapkan dapat memberikan kontribusi baik dalam proses belajar mengajar

\section{SIMPULAN DAN SARAN}

Berdasarkan data yang diperoleh, dari hasil penelitian yang terdiri dari validasi ahli, uji coba kelompok kecil dan uji coba kelompok besar serta pembahasan dari hasil penelitian, maka peneliti dapat menarik kesimpulan bahwa :

1. Model pembelajaran keterampilan lempar tangkap softball menggunakan media pembelajaran pada sekolah menengah atas sebanyak 30 model yang diterapkan dalam pembelajaran keterampilan lempar tangkap softball 
menggunakan media pembelajaran dapat meningkatkan keterampilan lempar tangkap softball

2. Model keterampilan lempar tangkap softball yang telah dibuat dinyatakan efektif dan layak digunakan. Karena dari hasil penelitian bahwa terdapat perbedaan hasil data dari kelompok eksperimen dengan kelompok kontrol.

\section{DAFTARPUSTAKA}

Akbar, A., \& Faz'ul, M. (2015). Pengembangan modelmodel permainan lempar dan tangkap untuk pembelajaran softball bagi siswa kelas VIII SMP Negeri 1 Malang/Muh. Faz'ul Akbar A (Doctoral dissertation, Universitas Negeri Malang).

American Sport Education Program. 2009. Coaching Softball Technical and Tactical Skills. New Zealand: Human Kinetic.

American Sport Education Program. 2007. Coaching Youth Softball. New Zealand: Human Kinetic.

Borg and Gall. 1983. Educational Research An Introduction. New York, Longman.

Diane Potter. 2009. Softball Steps To Success. United States: Human Kinetic.

Judi Garman. 2011. Softball Skill and Drill. United States of America: Human Kinetic.

Michele Smith. 2008. Coach Guide To Game winning Softball Drills. United States of America: McrawHill.

Rick Noren. 2005. Softball Fundamental. New Zealand: Human Kinetic.

Samsudin. 2008. Pembelajaran Pendidikan Jasmani Olahraga dan Kesehatan SMA/MA. Jakarta: Litera.

Samsudin. 2014. Desain Kurikulum Pendidikan Jasmani Olahraga dan Kesehatan. Jakarta: Litera.

Samsudin. 2014. Media Pembelajaran Pendidikan Jasmani. Jakarta: Litera.

Sugiyanto. 2007. Perkembangan Anak dan Remaja. Jakarta: MendfkBdel keterampilan lemp

Sugiyono. 2011. Metode Penelitian Kuantitatif, Kualitatif dan $R \& D$. Bandung: Alfabeta.

Muhammad Aniq Asqof. 2015. "Perbedaan Latihan Melempar dengan Sasaran Berpindah dan Latihan Lemparan Samping dengan Berpasangan Terhadap Akurasi Lemparan Samping pada Anggota Unit Kegiatan Mahasiswa Softball UNNES," Journal of Sport Sciences and Fitness, Vol.4 (1), hal. 44.

Ni Putu Ayu. 2016. "Meningkatkan Motivasi Gerak Dalam Permainan Bola Softball Dengan Modifikasi Alat Pada Siswa Kelas VIII SMP Muhammadiyah 2 Yogyakarta", Jurnal PendidikanJasmani Indonesia, Vol. 12, (1), hal. 11.

Soegiyanto. 2005. "Pengembangan Alat Ukur Keterampilan Dasar Bermain Softball", Cakrawala Pendidikan, Vol. 29 (1), hal. 281.

Waham Soetahir. 2005. "Modifikasi Permainan Softball di Sekolah Dasar", Jurnal Pendidikan Jasmani Indonesia, Vol. 3, (1), hal. 82.

Widiastuti, W., Hamdallah, N. B., \& Pradityana, K. (2018). Model Pembelajaran Lempar Tangkap Untuk Siswa Sekolah 
Dasar. Jurnal Pendidikan Dasar, 9(1), 166-176.

Widiati Amali. (2016). "Pengembangan Model Pembelajaran Lob Bulutangkis Untuk Siswa Sekolah Menengah Pertama", Jurnal
IPTEK Olahraga, Vol. 18, (3), hal. 266.

Yudhi, N. P., Suherman, A., \& Saptani, E. (2018). Pengaruh. Modifikasi. Bola. Terhadap. Lempar. Tangkap. Pada.. Permainan bola. Kasti. SpoRTIVE, 1(1), 391-400. 